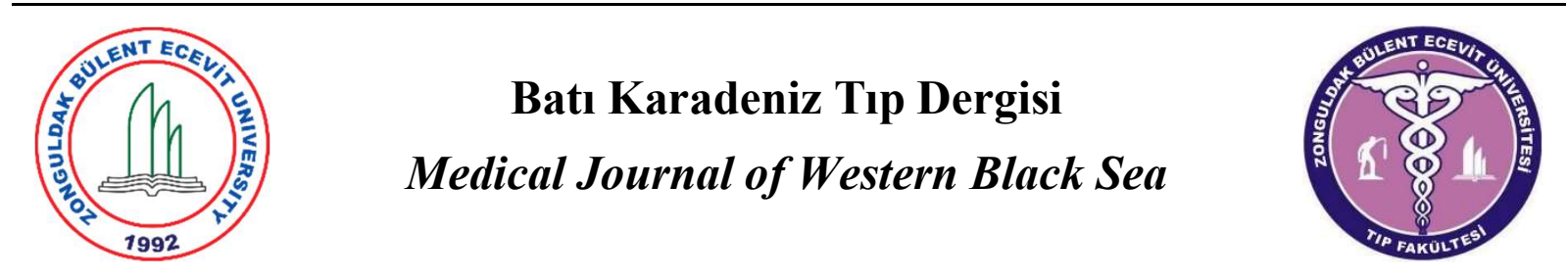

Araştırma Makalesi

Doi: $10.29058 /$ mjwbs.2019.2.3

\title{
Tıp Fakültesi Klinik Öncesi Öğrencilerde İnternet Bağımlılı̆̆ının Sosyodemografik Özellikler İle İlişkisi
}

\author{
Ahmet Erim Erdoğan a, Alperi Orhon ${ }^{\text {a }}$, Benazir Farhadi a, Abdülkerim Horat ${ }^{\text {a }}$, Ahmet Melih Özgül a \\ Ethem Burak Özkan ${ }^{a}$, Serhat Saygın ${ }^{\text {a }}$, Fürüzan Köktürk ${ }^{\text {b }}$ \\ ${ }^{a}$ Zonguldak Bülent Ecevit Üniversitesi Tip Fakültesi Dönem 4 Öğrencileri, Zonguldak, Türkiye. \\ ${ }^{b}$ Zonguldak Bülent Ecevit Üniversitesi Tıp Fakültesi, Biyoistatistik Anabilim Dalı, Zonguldak, Türkiye.
}

ORCíD : Ahmet Erim Erdoğan 000000018355 8592, Alperi Orhon 000000033563 5017, Benazir Farhadi 000000034574 791X, Abdülkerim Horata 000000021525 5327, Ahmet Melih Özgül 000000027385 4686, Ethem Burak Özkan 00000002 5908 3280, Serhat Saygın 000000033995 2132, Fürüzan Köktürk 0000000225807770

\begin{tabular}{|c|c|}
\hline $\begin{array}{l}\text { M A K A L E } \\
\text { B İ L G İ S I }\end{array}$ & Ö Z \\
\hline Gönderilme Tarihi: & Amaç: $\mathrm{Bu}$ çalışmada, çağımızın büyük problemlerinden biri olan \\
\hline 28.08 .2019 & internet bağımlılığının, Bülent Ecevit Üniversitesi Tıp Fakültesi \\
\hline Revizyon: & klinik öncesi öğrencilerinin hayatında ne ölçüde yer tuttuğunun \\
\hline 29.08 .2019 & belirlenmesi ve bu durumun sosyodemografik özellikler ile olan \\
\hline Kabul: & ilişkisinin incelenmesi hedeflenmiştir. \\
\hline 31.08 .2019 & Gereç ve Yöntemler: Araştırmada, Dönem I, II ve III. sınıflarında \\
\hline Sorumlu Yazar: & $\begin{array}{l}\text { okuyan toplam } 558 \text { ogrencı araştırma evrenını oluşturmuştur. Anket } \\
\text { formunda sosyodemografik özellikler, aile ile iliskilere ve internet }\end{array}$ \\
\hline Fürüzan Köktürk & kullanımına yönelik soruların yanı sıra internet bağımlılığını \\
\hline furuzan.kokturk@beun.edu.tr & belirlemek için 30 sorudan oluşan İnternet Bağımlılığı Ölçeği \\
\hline Anahtar Kelimeler: & kullanılmıştır. \\
\hline Tıp fakültesi ögrencileri, internet & Bulgular: Çalışmaya Dönem I'den 152 (\%34.7), Dönem II'den 148 \\
\hline bağımlılı̆̆g, problemli internet & (\%33.8), Dönem III’ten $138(\% 31.5)$ olmak üzere toplam 438 \\
\hline kullanımı, davranış bağımlılıkları & (\%78.4) öğrenci katılmıştır. Katılımcıların \% 55.2'si (n=239) kadın, \\
\hline & \%44.8'i $\quad(n=194)$ erkek öğrencilerden oluşmaktadır. İnternet \\
\hline & bağımlılığı ölçeği de uygulanan öğrencilerin \%24.0'ü internet \\
\hline & $\begin{array}{l}\text { bağımlısı olarak bulunmuştur. Bağımlı olan }(n=105) \text { ve olmayan } \\
\text { grupta }(n=333) \text { sadece sinıf tekrarı yapma durumu ve aile ile }\end{array}$ \\
\hline & görüşme şekli bakımından fark anlamlı bulunmuşken (sırasıyla \\
\hline & $\mathrm{p}=0.029$ ve $\mathrm{p}=0.019$ ), diğer sosyodemografik özellikler bakımından \\
\hline & $\begin{array}{l}\text { gruplar oiroirlerine benzer bulunmuştur. } \\
\text { Sonuc: Tıp fakültesi klinik öncesi öğrencileri arasında \%24 }\end{array}$ \\
\hline & oranında saptadığımız internet bağımlılığı dikkat edilmesi gereken \\
\hline & \\
\hline
\end{tabular}

(C) 2019 Zonguldak Bülent Ecevit Üniversitesi Her hakkı saklıdır. 


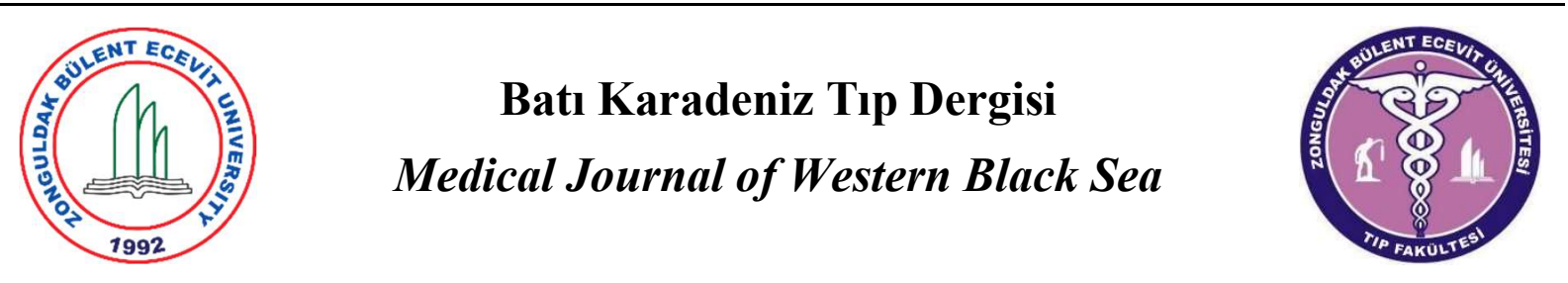

Research Article

Doi: $10.29058 /$ mjwbs.2019.2.3

\title{
The Relationship Between Internet Addiction and Sociodemographic Characteristics in Pre-Clinical Students of Medical Faculty
}

\author{
Ahmet Erim Erdoğan ${ }^{\text {a }}$, Alperi Orhon ${ }^{\text {a }}$, Benazir Farhadi a, Abdülkerim Horat ${ }^{\text {a }}$, Ahmet Melih Özgül a, \\ Ethem Burak Özkan ${ }^{a}$, Serhat Saygın ${ }^{\text {a }}$, Fürüzan Köktürk ${ }^{\text {b }}$ \\ ${ }^{a}$ Zonguldak Bulent Ecevit University School of Medicine Fourth Grade Students, Zonguldak, Turkey. \\ ${ }^{b}$ Zonguldak Bulent Ecevit University School of Medicine, Department of Biostatistics, Zonguldak, Turkey.
}

\begin{tabular}{l} 
A R T I C L E \\
I N F O R M A T I O N \\
\hline Date of Submission \\
28.08 .2019 \\
Revision: \\
29.08 .2019 \\
Accepted: \\
31.08 .2019 \\
Correspondence Author: \\
Fürüzan Köktürk \\
furuzan.kokturk@beun.edu.tr \\
\hline Key Words: \\
Medical students, internet \\
addiction, problematic internet \\
use, behavioral addictions
\end{tabular}

\begin{abstract}
A B S T R A C T
Aim: In this study, it is aimed to determine the extent of internet addiction, which is one of the major problems of our age, in the life of pre-clinical students of Bülent Ecevit University Faculty of Medicine and to investigate the relationship between this situation and sociodemographic characteristics.

Material and Methods: In this study, a total of 558 students studying in $1 \mathrm{st}$, 2nd and 3rd grades formed the research population. In the questionnaire form, 30 questions were used to determine the internet addiction as well as sociodemographic characteristics, family relations and internet use questions.

Results: A total of 438 students (78.4\%), 152 (34.7\%) from first grade, 148 (33.8\%) from second grade, 138 (31.5\%) from third grade participated in the study. $55.2 \%(\mathrm{n}=239)$ of the participants were female and $44.8 \%(n=194)$ were male students. $24.0 \%$ of the students who applied internet addiction scale were found to be internet addicts. In the dependent $(\mathrm{n}=105)$ and non-dependent group $(\mathrm{n}=333)$, the difference was found to be significant only in terms of repetition and the way of interviewing with the family ( $p=0.029$ and $p=0.019$, respectively).

Conclusion: Among the pre-clinical students of the medical faculty, internet addiction, which we found at a rate of $24 \%$, is an important problem that needs attention.
\end{abstract}




\section{Giriş}

İnternetin ortaya çıkışı dünyada her türlü bilgiye sınırsız bir erişim sağlamış, bilgi paylaşımını kolaylaştırmış ve araştırmacıların olanaklarını arttırmıştır. Ancak internetin çok hızla yaygınlaşması beraberinde bazı olumsuz sonuçları da getirmiştir. Bu olumsuz sonuçlardan birisi aşırı internet kullanımıdır. Dünya üzerinde milyonlarca internet kullanan kişiden bazıları internet bağımlısı" olarak tanımlanmaktadır (1). İnternet bağımlılığı kavramı ilk kez Goldberg tarafindan 1995 yılında kullanılmıştır. Ancak "İnternet Bağımlılı̆ğ Hastalı̆̆ı" kavramını ilk gündeme getiren uzmanlardan biri Young'dır (2). "İnternet bağımlılığı genel olarak internetin aşırı kullanılması isteğinin önüne geçilememesi, internete bağlı olmadan geçirilen zamanın önemini yitirmesi, yoksun kalındığında aşırı sinirlilik hali ve saldırganlık olması ve kişinin iş, sosyal ve ailevi hayatının giderek bozulması" olarak tanımlanabilir (3). Son yıllarda adını sıkça duyduğumuz bu bağımlılık, sosyoloji, psikoloji ve iletişim başta olmak üzere farklı disiplinlerden araştırmacıların dikkatini çeken önemli bir çalışma alanı haline gelmiştir. Bilgisayarla ilerleyen toplum, öğrencilerin teknolojik bir çevrede işlem yapabilme yeterliliklerini geliştirmelerini gerektirmektedir. Ancak, internet kullanımının psikolojik olarak bağımlılık taşıyan özelliklerinin sayısında görülen artış, eğitimciler ve psikologların internetin insanların sağlığı üzerindeki etkisi konusunda artan bir kaygıya kapılmalarına sebep olmaktadır (4). İnternet bağımlılı̆̆ açısından öğrencilerin çok riskli bir noktada durdukları görülmektedir. Türkiye İstatistik Kurumu'nun 2012 Yılı Hane halkı Bilişim Teknolojileri Kullanımı Araştırması sonuçlarına göre bilgisayar ve internet kullanım oranının en yüksek olduğu yaş grubu 16-24 tür. Eğitim durumuna göre en fazla internet kullanım oranı \% 93.0 ile yüksekokul, fakülte ve daha üstü bireylerdedir. Öğrencilerin profesyonel gelişimi konusunda internetin vaat ettikleri ve okul hayatlarında internetin ayrılmaz bir parça haline gelmesi; yerleşkelerde internet kullanımının önünü açmıştır. Bu durum, öğrencilerin patolojik internet kullanımı karşısında risk altında kalma ihtimallerini artırmıştır (5).

$\mathrm{Bu}$ çalışmada, çağımızın en büyük problemlerinden biri olan internet bağımlllı̆̆ının, Bülent Ecevit Üniversitesi Tıp Fakültesi klinik öncesi öğrencileri arasındaki sıklığının belirlenmesi ve internet bağımlılığını etkileyen sosyodemografik özelliklerin saptanması amaçlanmıştır.

\section{Gerec ve Yöntemler}

Kesitsel tipteki bu araştırmanın evrenini Bülent Ecevit Üniversitesi Tıp Fakültesi’nin Dönem I, II ve III. sınıflarında okuyan toplam 558 öğrenci oluşturmuştur. Çalışma, Kasım 2018 ile Mayıs 2019 tarihleri arasında gerçekleştirildi. Örneklem çekilmesine gerek duyulmadan evrenin tamamına ulaşılması hedeflendi. Gönüllülük esasına göre çalışmayı kabul eden öğrencilere internet bağımlılığı sıklı̆ğ ve etkileyen etmenleri ortaya koymay amaçlayan bir anket formu yüz yüze görüşme yoluyla doldurtuldu ve çalışmaya katılım oranı \%78.4 olarak gerçekleşti. Zonguldak Bülent Ecevit Üniversitesi İnsan Araştırmaları Etik Kurulu'ndan onay alındıktan sonra veriler toplanmaya başlandı (Protokol no: 555). Veri toplama arac1 olarak araştırmacılar tarafindan oluşturulan, araştırmanın bağımsız değişkenleri olan 21 sorudan oluşan sosyodemografik özellikleri içeren sorular, araştırmanın bağımlı değişkeni olan internet bağımlılığı durumunu ölçen Nichols ve Nicki (2004) tarafindan geliştirilen İnternet Bağımlılık Ölçeği (Internet Addiction Scale) kullanıldı. Ölçek, Temel Bileşenler Analiz (Principle-Component Analysis) yöntemi ile tek faktör altında toplanan 31 maddeden oluşmaktadır. Ölçeğin orijinaline ilişkin iç tutarlılık katsayısı (Cronbach alfa) 0.95 ve ölçeğe ilişkin açıklanan varyans $\% 46.50$ olarak tespit edilmiştir. Ölçeğe ilişkin maddelerin tümü olumlu olup, beşli likert dereceleme ile ölçeklenmiştir. Ölçeğin Türkçeye uyarlanması ve geçerlilik ve güvenirlik çalışması Murat Kayri ve Selim Günüç tarafindan 2009 'da yapılmıştır. Türkçeye uyarlanmış hali 30 sorudan oluşmaktadır. Ölçeğin bağımlılık taban puanı 90 olarak belirlenmiştir. Ölçeğe ilişkin güvenirlik katsayısı da (Cronbach alfa) 0.93 ve açıklanan varyans \%33.95 olarak tespit edilmiştir (6).

Araştırmada elde edilen verilerin istatistiksel analizinde SPSS 19.0 programı kullanıldı. Elde edilen tanımlayıcı istatistikler; sayısal değişkenler için aritmetik ortalama ve standart sapma, sözel değişkenler için sayı ve yüzde şeklinde ifade edildi. Bağımlı ve bağımlı olmayan grupların karşılaştırılmasında Pearson Ki-kare ve Fisher Kesin $\mathrm{Ki}$-kare testlerinden faydalanıldı ve tüm istatistiksel değerlendirmeler için $\mathrm{p}<0.005$ değeri anlamlı kabul edildi. 


\section{Bulgular}

Çalışmaya katılanların \%34.7'si ( $\mathrm{n}=152)$ Dönem I, \%33.8'si (n=148) Dönem II ve \%31.5'i ( $\mathrm{n}=138)$ Dönem III öğrencisiydi. Öğrencilerin yaş ortalaması $20.8 \pm 1.8$, yaş aralığı ise $18-30$ arasında değişmekteydi. Katılanların \%44.8'i erkek, \%55.2'si kadın öğrencilerdi. Sınıf tekrarı yapan öğrencilerin oranı \%39.5 olarak bulundu. Katılan öğrencilerin yarıya yakını (\%48.0) yurt ya da apartlarda kalmaktaydı. Öğrencilerin \%42.6'sının gelir düzeyi 5000 TL'den fazla iken, geliri 1500 TL'nin altında olan öğrenci oranı \%7.5 olarak gözlendi. Anne ve babanın hayatta olup olmadığı sorusuna ise tamamına yakını hayatta cevabını verdi (anne için \%97.3, baba için \%95.4). Anne ve babaların çoğu üniversite mezunu olup bu oran annelerde \%35.2, babalarda \%53.1 olarak tespit edildi. Çalışmaya katılan öğrencilere aile ile ilişkiler ve internet kullanımları ile ilgili sorular da yöneltildi. Öğrencilerin büyük bir çoğunluğu aile ile görüşme yolu olarak telefonu tercih ederken (\%61.8), $\% 14.7$ 'si internetten görüşmeyi tercih ettiklerini belirtti. Ailemle her gün görüşüyorum diyenlerin oranı \%55.6 iken, yılda birkaç kez diyenlerin oranı $\% 0.9$ olarak bulundu. "İnternette geçirdiğiniz süreyi sınırlandırmada sorun yaşadığınızı düşünüyor musunuz?" sorusuna öğrencilerin yarıdan fazlası (\%51.6) evet cevabını verdi. "İnternetin hayatınızdaki önemi nedir?" sorusuna ise öğrencilerin büyük çoğunluğu olmalı cevabını verirken, olmasa da olur diyenlerin oranı \%8.3'tü. Öğrencilere ait tanımlayıcı bilgiler Tablo 1'de verildi.

Tablo 1. Katılımcıların tanımlayıcı özellikleri

\begin{tabular}{|c|c|c|c|}
\hline & & $\begin{array}{l}\text { Ortalama } \pm \text { Std } \\
\text { Sapma }\end{array}$ & Min - Maks \\
\hline \multicolumn{2}{|l|}{ Yaş } & $20.8 \pm 1,8$ & $18-30$ \\
\hline \multicolumn{2}{|l|}{ Kardeş sayısı } & $1.6 \pm 1.1$ & $0-8$ \\
\hline \multirow{2}{*}{\multicolumn{2}{|c|}{ Okuyan kardeş sayısı }} & $1.1 \pm 0.9$ & $0-6$ \\
\hline & & $\mathbf{n}$ & $\%$ \\
\hline \multirow[t]{3}{*}{ Sinıf } & Dönem I & 152 & 34,7 \\
\hline & Dönem II & 148 & 33,8 \\
\hline & Dönem III & 138 & 31,5 \\
\hline \multirow[t]{2}{*}{ Cinsiyet } & Erkek & 194 & 44,8 \\
\hline & Kadın & 239 & 55,2 \\
\hline \multirow[t]{2}{*}{ Sinıf tekrarı yapıldı mı? } & Evet & 173 & 39,5 \\
\hline & Hayır & 265 & 60,5 \\
\hline \multirow[t]{4}{*}{ İkamet edilen yer } & Yurt/Apart & 209 & 48,0 \\
\hline & Evde arkadaşları ile & 57 & 13,1 \\
\hline & Evde tek başına & 109 & 25,1 \\
\hline & $\begin{array}{l}\text { Ailesi ya da akrabaları } \\
\text { ile }\end{array}$ & 60 & 13,8 \\
\hline \multirow[t]{4}{*}{ Gelir düzeyi } & $<1500$ & 32 & 7,5 \\
\hline & $1501-2500$ & 47 & 11,0 \\
\hline & $2501-5000$ & 166 & 38,9 \\
\hline & $>5000$ & 182 & 42,6 \\
\hline
\end{tabular}




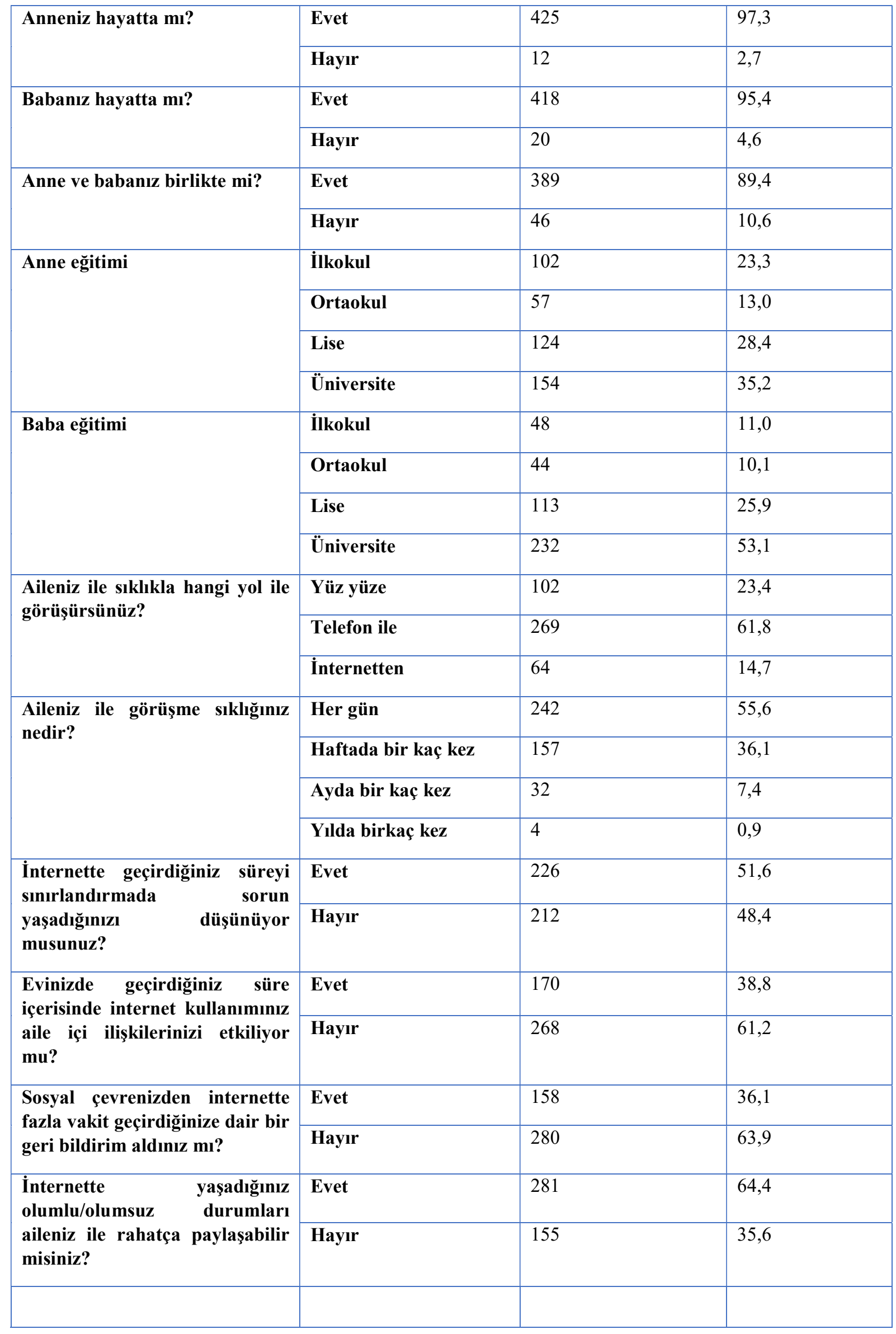




\begin{tabular}{|l|l|l|l|}
\hline \multirow{4}{*}{$\begin{array}{l}\text { İternette yaşadı̆̆ınız sorunları } \\
\text { en rahat kiminle paylaşırsınız? }\end{array}$} & Ailem ile & 118 & 27,1 \\
\cline { 2 - 4 } & Arkadaşlarım ile & 269 & 61,8 \\
\cline { 2 - 4 } & Eğiticilerim ile & 6 & 1,4 \\
\cline { 2 - 4 } & Hiç kimseyle & 34 & 7,8 \\
\cline { 2 - 4 } & Diğer & 8 & 1,8 \\
\hline \multirow{4}{*}{$\begin{array}{l}\text { İnternetin hayatınızdaki önemi } \\
\text { nedir? }\end{array}$} & Mutlaka olmalı & 153 & 35,2 \\
\cline { 2 - 4 } & Olmalı & 246 & 56,6 \\
\cline { 2 - 4 } & Olmasa da olur & 36 & 8,3 \\
\hline
\end{tabular}

İnternet Bağımlılığı Ölçeği puanları hesaplandıktan sonra kesme noktası 90 olarak alındığında öğrencilerin \%24'ünün ( $\mathrm{n}=105)$ bağımlı, \%76'sının ( $\mathrm{n}=333)$ ise bağımlı olmayan grupta yer aldıkları görüldü. Bağımlılık durumunun sınıflara göre dağılımı incelendiğinde, Dönem I öğrencilerinin \%22.4'ünün, Dönem II öğrencilerinin \%24.3'ünün, Dönem III öğrencilerinin ise \%25.4'ünün bağımlı grupta oldukları gözlendi. Sinıflar arasındaki fark istatistiksel olarak anlamlı bulunmadı $(\mathrm{p}=0.831)$. Erkek öğrencilerde bağımlılık oranı (\%25.8) kadın öğrencilere göre (\%22.6) fazla olmasına rağmen aradaki fark anlamlı değildi $(\mathrm{p}=0.441)$. Sınıf tekrarlama durumu ile bağımlılık arasındaki ilişki sorgulandığında sınıf tekrarı yapan öğrencilerde bağımlılık oranının (\%29.5) yapmayanlara göre $(\% 20.4)$ anlamlı derecede yüksek olduğu gözlendi $(\mathrm{p}=0.029)$.

Öğrencilerde \%31.6 oranı ile en fazla öğrenci evinde arkadaşları ile kalanlarda bağımlılık gözükürken en az \%20.0 ile ailesi ya da akrabas1 yanında kalan öğrencilerde saptandı. Kalınan yer bakımından bağımlı olanlarla olmayanlar arasındaki fark anlamlı bulunmadi $(\mathrm{p}=0.367)$.

Gelir seviyesi arttıkça bağımlılık oranlarının da arttığı gözlenirken bağımlılık oranları bakımından gelir seviyeleri arasındaki fark anlamlı değildi $(\mathrm{p}=0.490)$.
Anne ve babanın hayatta olması bakımından bağımlı olanlarla olmayanların oranları da benzer bulundu (sirasiyla $p=0.309$ ve $p=0.794$ ). Anne babanın beraber olması ile bağımlılık arasında da anlamlı bir ilişki mevcut değildi $(\mathrm{p}=0.093)$. Anne ve babası beraber olan öğrencilerin \%25.4'ünde bağımlılık durumu saptanmışken ayrı olanlarda bu oran \%13.0 idi.

Çalışmaya katılan öğrenciler arasında bağımlı grupta yer alanların annelerinin en fazla oranda (\%36.8) ortaokul mezunu oldukları gözlenirken ilkokul, lise ve üniversite mezunlarının oranları yaklaşık olarak benzer bulundu. Baba eğitimi sorgulandığında ise bağımlı bulunan öğrencilerin çoğunun (\%34.1) baba eğitim düzeylerinin yine ortaokul olduğu belirlendi. Anne ve baba eğitimleri bakımından gruplar arasındaki fark anlamlı değildi (sirasiyla $\mathrm{p}=0.099$ ve $\mathrm{p}=0.081$ ).

Öğrenciler aileleriyle görüşme şekilleri ve sıklığı bakımından incelendiklerinde internet aracılığı ile görüşen öğrencilerin oranı (\%35.9), yüz yüze ve telefonla görüşen öğrencilere göre anlamlı derecede yüksek bulunurken $(\mathrm{p}=0.019)$, görüşme sıklığı bakımından gruplar arasındaki fark anlamlı bulunmadı $(\mathrm{p}=0.612)$. Sosyodemografik özellikler bakımından bağımlı ve bağımlı olmayan grupların karşılaştırılmasına ait sonuçlar Tablo 2'de gösterildi. 
Tablo 2. Sosyodemografik özellikler bakımından grupların karşılaştırılması

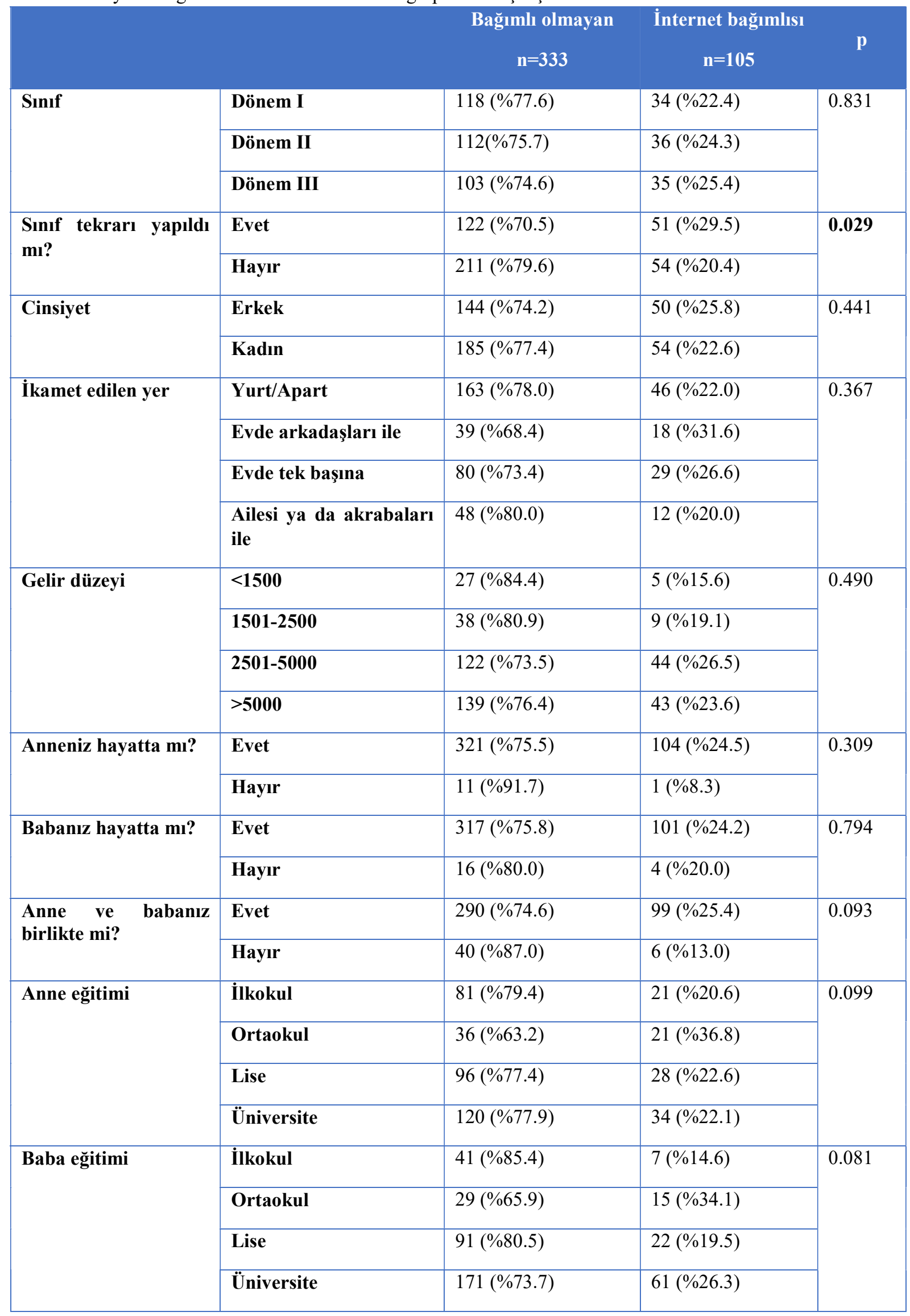




\begin{tabular}{|c|c|c|c|c|}
\hline \multirow{3}{*}{$\begin{array}{lrr}\text { Aileniz } & \text { ile } & \text { stklıkla } \\
\text { hangi } & \text { yol } & \text { ile } \\
\text { görüşürsünüz? } & \end{array}$} & Yüz yüze & $74(\% 72.5)$ & $28(\% 27.5)$ & \multirow[t]{3}{*}{0.019} \\
\hline & Telefon ile & $215(\% 79.9)$ & $54(\% 20.1)$ & \\
\hline & İnternetten & $41(\% 64.1)$ & $23(\% 35.9)$ & \\
\hline \multirow{4}{*}{$\begin{array}{l}\text { Aileniz ile görüşsme } \\
\text { sıklığınız nedir? }\end{array}$} & Her gün & $178(\% 73.6)$ & $64(\% 26.4)$ & \multirow[t]{4}{*}{0.612} \\
\hline & Haftada bir kaç kez & $123(\% 78.3)$ & $34(\% 21.7)$ & \\
\hline & Ayda bir kaç kez & $26(\% 81.3)$ & $6(\% 18.8)$ & \\
\hline & Yılda birkaç kez & $3(\% 75.0)$ & $1(\% 25.0)$ & \\
\hline
\end{tabular}

\section{Tartışma}

Ülkemizde de diğer ülkelerdeki gibi teknolojinin gelişmesiyle birlikte internet kullanımı hızla yaygınlaşmakta, faydalarının yanında hatalı kullanımı ile bireyleri pek çok yönden etkisi altına almaktadır. Netice itibariyle bu durum bizleri internet bağımlılı̆̆ 1 oluşturma potansiyeliyle yüz yüze bırakmaktadır. Türkiye'de yapılan bazı çalışmalarda üniversite öğrencilerinde internet bağımlılı̆̆ $\% 1.2$ (7) gibi çok düşük oranda bulunurken bazı çalışmalarda \%18 (8) ve \%80 (9) gibi oranlara da rastlanılmaktadır. Bu farklılığın sebebi farklı yaş grupları, araştırma yöntemleri ve farklı zaman ve yerlerde yapılmış olmaları olabileceği gibi evrensel bir İnternet Bağımlılığı Ölçeği'nin kullanılmaması da olabilir. Bizim çalışmamızda bu oran \%24 olarak bulundu.

Çalışmaya dahil edilen klinik öncesi sınıflarda bağımlılık oranları yaklaşık olarak benzer bulunurken sınıf arttıkça bağımlılık oranının da arttı̆̆ gözlendi. Fakat sınıflar arasındaki fark istatistiksel olarak anlamlı bulunmadı. Sinıf tekrarı yapan öğrencilerde ise yapmayanlara göre bağımlılık oranı anlamlı derecede yüksek olarak saptand. Ergin A. ve arkadaşları tarafindan 2013 y1lında 386 Tıp öğrencisi üzerinde yaptıkları çalışmada tüm sınıflar çalışmaya dahil edilmiş, bu çalışmada da bağımlılık oranları bakımından sınıflar arasındaki fark anlamlı bulunmamıştır $(\mathrm{p}=0.885)$ (10). Aynı çalışmada yine bizim çalışmamıza benzer olarak erkeklerde bağımlılık oranları kadın öğrencilere göre daha yüksek bulunurken aradaki fark anlamlı değildir $(p=0.371)$. Aslan $E$. ve arkadaşları tarafından Mersin Üniversitesi'nin ana kampüsünde yapılan çalışmada öğrencilere Young'ı İnternet Bağımlılı̆̆ı Ölçeği (IBÖ) uygulanmış, alınan puanlara göre internet bağımlısı, riskli internet kullanıcısı ve ortalama internet kullanıcısı olarak gruplanan öğrenciler sosyodemografik özellikler ve internet kullanım özellikleri yönünden karşılaştırılmışlardır (11). Bu çalışmada sekiz fakülte ve 2 meslek yüksekokulu çalışmaya dahil edilmiş ve toplam 910 öğrenci ile çalışılmıştır. Çalışmada cinsiyetler arasındaki fark anlamlı bulunurken $(\mathrm{p}=0.001)$, erkek öğrencilerde riskli internet kullanımının kadın öğrencilere göre yüksek oluşu göze çarpmaktadır. Aynı çalışmada bizim çalışmamıza benzer olarak ikamet durumu ve gelir düzeyi ile ilişkiler anlamlı bulunmamıştır (sırasıla $\mathrm{p}=0.875$ ve $\mathrm{p}=0.994$ ). Balcı Ş, ve Gülnar B. tarafından 2009 yılında üniversite öğrencilerinde internet bağımlılı̆̆ araştırıldığ 1 araştırmada yine ikamet edilen yer ve gelir düzeyi ile anlamlı bir ilişki gözlenmemiştir $(\mathrm{p}>0.05)(5)$.

Çalışmamızda öğrencilerin bağımlılık durumuna etki edebileceği düşünülen diğer faktörler olan anne ve babanın hayatta olup olmaması ile medeni durumları da sorgulanmış fakat anlamlı bir ilişki bulunamamıştır. Pektaş İ ve Mayda AS tarafindan 2017 yılında yapılan çalışmada Düzce Üniversitesi Tıp Fakültesi 1. ve 6. sinıflara Young İnternet Bağımlılık Testi Kısa Formu uygulanmış, puanlar sayısal olarak kaydedilmiştir. Çıkan sonuçlara göre puan ortalamaları bakımından anne ve babanın medeni durumları arasında anlamlı bir farklılık gözlenmemiştir $(\mathrm{p}=0.230)$ (12). Turan RT tarafindan yapılan tez çalışmasında ise Başkent Üniversitesi öğrencileri arasından seçilen 397 öğrenci üzerinde çalışılmış ve anne ve babalarının medeni durumlarının bağımlılık durumu ile ilişkili olduğu gösterilmiştir $(\mathrm{p}=0.004)$. Anne ve babası boşanmış ya da dul olanlar içinde internet bağımlılığı/muhtemel bağımlılık riski olan üniversite öğrencilerinin yüzdesi anne ve babası evli olanlardan anlamlı olarak yüksek bulunmuştur (13).

Bağımlılığa etkisi olabileceği düşünülen diğer faktörler olan anne ve baba eğitimleri bakımından da gruplar arasındaki anlamlı bir farkl1lığa rastlanmamıştır. Bağımlı olan grupta çoğunlukla hem annenin hem de babanın ortaokul mezunu olmaları dikkat çekicidir. Ergin A. ve arkadaşları 
tarafından tıp fakültesi öğrencilerinde yapılan çalışmada da benzer şekilde anne ve baba eğitimlerinin bağımlılığa etkisinin olmadığı saptanmıştır ( $p>0.05)(9)$.

Aile ile görüşme biçimi ve sıklığının da bağımlılıkta etkili olabileceği düşünülmüş, ailesi ile internet yoluyla görüşenlerde bağımlılık oranı anlamlı olarak fazla bulunmuştur. Fakat görüşme sıklığı bakımından gruplar arasında herhangi bir farklılık gözlenmemiştir.

Araştırmamızın en önemli kısıtlılı̆̆ evrenin \%74.8'ine ulaşılmış olmasıdır. Uluslararası kullanılan ve Türkiye'de geçerliliği ve güvenilirliği ispatlanmış bir ölçeğin kullanılmış olması ise çalışmamızın güçlü yanıdır.

Bilgisayar çağının getirdiği gereklilikler, öğrencilerin teknolojik bir ortamda işlem yapabilme yeterliliklerini geliştirmelerini gerektirmektedir. Ancak, internet kullanımının bağımlılık düzeyinde olanların sayısında görülen artış, internetin insanların sağlığı üzerindeki etkisi konusunda gün geçtikçe artan bir kaygı yaratmaktadır. Sonuç olarak, tıp fakültesi öğrencilerinde internet bağımlılığı hiç de azımsanmayacak oranda tespit edilmiş olup, internet bağımlılığı açısından üniversite öğrencilerinin de riskli bir noktada oldukları görülmektedir.

\section{Kaynaklar}

1. Öztürk Ö., ve ark. İnternet Bağımlılığı: Kliniği ve Tedavisi. Bağımlılık Dergisi. 2007; 8:36-41.

2. Gültutan Ş. İlköğretim 6., 7. ve 8. sınıf öğrencilerinin internet kullanma alışkanlıkları. Yüksek Lisans Tezi. Ankara Üniversitesi Eğitim Bilimleri Enstitüsü, Eğitim Bilimleri Anabilim Dalı Eğitimde Psikolojik Hizmetler Bilim Dalı Eğitim Psikolojisi Programı, Ankara, 2007.

3. Young KS. Internet addiction. Am Behav Sci. 2004; 48:402-441.

4. Nalwa K. and Anand A. Internet Addiction in Students. A Cause of Concern, Cyber Psychology and Behaviour. 2003; 6(6): 653-656.

5. Balcı Ş. ve Gülnar B. Üniversite Öğrencileri Arasında İnternet Bağımlılığı Ve İnternet Bağımlılarının Profili. Selçuk İletişim, 2009; 6(1):522.

6. Kayrı M. ve Günüç S. İnternet Bağımlılık Ölçeğinin Türkçeye Uyarlanması: Geçerlik Ve Güvenirlik Çalışması. Ankara Üniversitesi Eğitim Bilimleri Fakültesi Dergisi. 2009; 42(1):157-175.
7. Gökalp K. ve Gökalp S. Üniversite Öğrencilerinde İnternet Bağımlılı̆̆ı. Uluslararası Hakemli Psikiyatri ve Psikoloji Araştırmaları Dergisi. 2018; 12:91-102.

8. Niemz K., Griffiths M. and Banyard P. Prevalence of pathological internet use among university students and corre-lations with self-esteem, the general health questionnaire (GHQ), and disinhibition. Cyberpsychol Behav. 2005;8:562-573.

9. Young K.S. Internet addiction: the emergence of a new clinical disorder. Paper presented at:104th Annual Meeting of the American Psychological Association; 10 August 1996; Toronto, Canada.

10. Ergin A., Uzun S.U. ve Bozkurt A.İ. Tıp fakültesi öğrencilerinde internet bağımlılığı sıklığı ve etkileyen etmenler. Pamukkale Tip Dergisi. 2013; 6(3):134-142.

11. Aslan E. ve Yazıcı A. Üniversite Öğrencilerinde İnternet Bağımlılı̆̆ı ve İlişkili Sosyodemografik Faktörler. Klinik Psikiyatri. 2016; 19:109-117.

12. Pektaş İ. ve Mayda A.S. Tıp Fakültesi Öğrencilerinde İnternet Bağımlılığı Düzeyi ve Etkileyen Etmenler. Sakarya Tip Dergisi. 2018; 8(1):52-62.

13. Turan RT. Başkent Üniversitesi Öğrencilerinde İnternet Bağımlılı̆̆ı Sıklığı ve İlişkili Faktörler. Uzmanlık Tezi, Başkent Üniversitesi Tıp Fakültesi Aile Hekimliği AD. 2015, Ankara. 